\title{
Trigeminal somatosensory evoked potential test as an evaluation tool for infraorbital nerve damage
}

\author{
Woo Taik Hong ${ }^{1}$, \\ Jin-hee Choi ${ }^{1}$, \\ Ji Hyun Kim², \\ Yong Hun Kim ${ }^{1}$, \\ Chae-Eun Yang', \\ Jiye Kim ${ }^{1}$, \\ Sug Won Kim $^{1}$ \\ Departments of ${ }^{1}$ Plastic and \\ Reconstructive Surgery, and \\ ${ }^{2}$ Rehabilitation Medicine, Wonju \\ Severance Christian Hospital, Yonsei \\ University Wonju College of Medicine, \\ Wonju, Korea
}

\begin{abstract}
Background: Neurosensory changes are frequently observed in the patients with mid-face fractures, and these symptoms are often caused by infraorbital nerve (ION) damage. Although ION damage is a relatively common phenomenon, there are no established and objective methods to evaluate it. The aim of this study was to test whether trigeminal somatosensory evoked potential (TSEP) could be used as a prognostic predictor of ION damage and TSEP testing was an objective method to evaluate ION injury.

Methods: In this prospective TSEP study, 48 patients with unilateral mid-face fracture (only unilateral blow out fracture and unilateral zygomaticomaxillary fracture were included) and potential ION damages were enrolled. Both sides of the face were examined with TSEP and the non-traumatized side of the face was used as control. We calculated the latency difference between the affected and the unaffected sides.

Results: Twenty-four patients recovered within 3 months, and 21 patients took more than 3 months to recover. The average latency difference between the affected side and unaffected side was 1.4 and $4.1 \mathrm{~ms}$ for the group that recovered within 3 months and the group that recovered after 3 months, respectively.

Conclusion: Patients who suffered ION damage showed prolonged latency when examined using the TSEP test. TSEP is an effective tool for evaluation of nerve injury and predicting the recovery of patients with ION damage.
\end{abstract}

Keywords: Evoked potentials, somatosensory / Orbital fractures / Trigeminal nerve injuries

\section{INTRODUCTION}

Displaced mid-face fracture could cause a number of symptoms such swelling, loss of projection and diplopia. Furthermore, mid-face fractures often cause sensory damage to the infraorbital nerve (ION) as a result of infraorbital fissure, canal, or foramen involvement $[1,2]$. This symptom of ION damage could last for several weeks and could result in complete im-

\footnotetext{
Correspondence: Sug Won Kim

Department of Plastic and Reconstructive Surgery, Wonju Severance Christian Hospital, Yonsei University Wonju College of Medicine, 20 Ilsan-ro, Wonju 26426, Korea

E-mail: sugwonkim@yonsei.ac.kr
}

Received May 7, 2019 / Revised July 28, 2019 / Accepted July 30, 2019 pairment of the senses [3]. Hypoesthesia is most frequently followed by paresthesia and hyperesthesia. Neurosensory measurements such as the pin prick test or 2-point discrimination test are used to identify ION damage. However, these are subjective tests and the outcomes depend heavily on patient cooperation and the examiners' interpretation. In addition, it is difficult to estimate how long the patient's symptom would last. Trigeminal somatosensory evoked potential (TSEP) is a nerve conduction test used for lesions of the trigeminal nerve. When the peripheral nerve is stimulated in an area covered by the trigeminal nerve, the evoked potential travels to the trigeminal nuclei in the brain stem through the trigeminal ganglion. Subsequently, this information is sent to ventral posteromedial tha- 
lamic nucleus and finally stimulates the post central gyrus of the parietal lobe [4]. In the tests, 64 to 1,024 times the bipolar transcutaneous electrical stimulations are applied on the skin over the trajectory of somatosensory nerves. An averaging technique is used to eliminate noise from the brain and the surrounding muscle waves to develop a wave form (Fig. 1) [5,6]. Moderate intensity stimulation is also important to avoid muscle response.

For TSEP, three times the sensory threshold is recommended. The basic wave form of TSEP contains three phases (tri-phase), starting from negative deflection (N1), moving to positive deflection (P1), and finally ends in a negative deflection (N2). N1 represents the start of an evoked potential (check point of latency) and indicates axonal conduction. P1 represents the check point of amplitude at post central gyrus of parietal lobe and is the most reproducible measurement in this test $[7,8]$. N2 is the end point of an evoked potential. With this method, we can calculate a patient's latency difference of evoked potential between the affected and the unaffected sides.

In this study, we hypothesized the longer the difference of latency, the longer it will take for patients to recover. In addition, we investigated if the TSEP test could be used as a prognostic test for ION damage.

\section{METHODS}

\section{Patients}

Forty-eight patients (40 male and 8 female), aged between 15 and 79 years (mean age, 55.5 years) presented with ION damage as a result of unilateral mid-face fracture between January 2014 and December 2017 were included in this study. We included unilateral blow out fracture and unilateral zygomaticomaxillary fracture patients only. The average follow-up period for symptoms was 6.5 month (range, 1-21 months). Three patients were lost to follow-up during that period and these re-

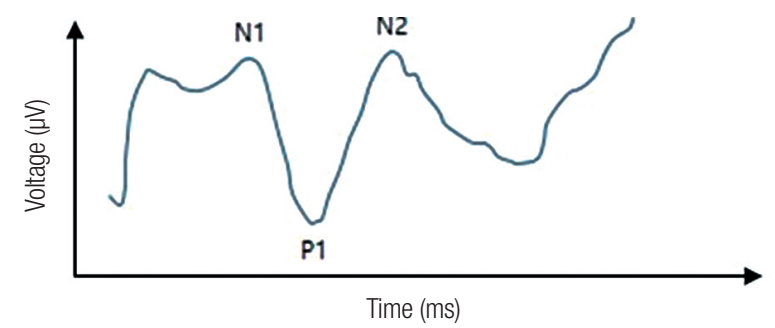

Fig. 1. Typical wave form of trigeminal somatosensory evoked potential. N1, starting point of the evoked potential (check point of latency), which indicate axonal conduction; P1, check point of amplitude at the post central gyrus of the parietal lobe; N2, end point of the evoked potential. sults were excluded. Written informed consent was obtained from all patients for the publication of results.

\section{Trigeminal somatosensory evoked potential}

The patients were examined with TSEP on both sides of the face, using the non-traumatized side as control. TSEP was measured with Key Point (Medtronic Inc., Minneapolis, MN, USA) while the patients were comfortable and relaxed (Fig. 2). Surface electrode used for stimulation was positioned at the affected area of ION damage. A 12-mm needle electrode was placed at the forehead and used for recording (Fig. 3). In this test, 200 times of $3.1 \mathrm{~Hz}$ bipolar transcutaneous electrical stimulations were applied to develop an average wave form. Three times the sensory threshold was chosen in order to eliminate background brain and muscle noises. The standard tri-phase wave form was observed in all tests. N1 represented well as the start point of the evoked potential and $\mathrm{P} 1$ also did its role quite well by indi-

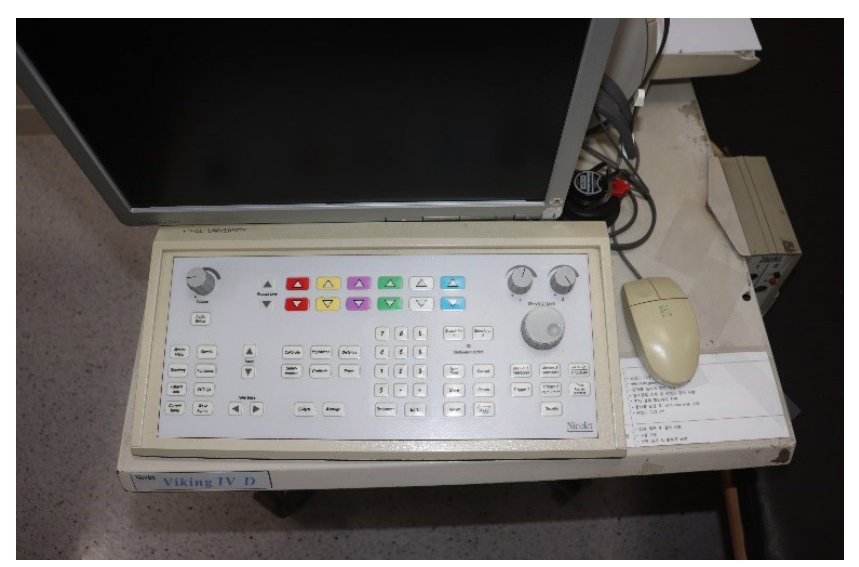

Fig. 2. Trigeminal somatosensory evoked potential measuring machine (Medtronic Inc., Minneapolis, MN, USA).

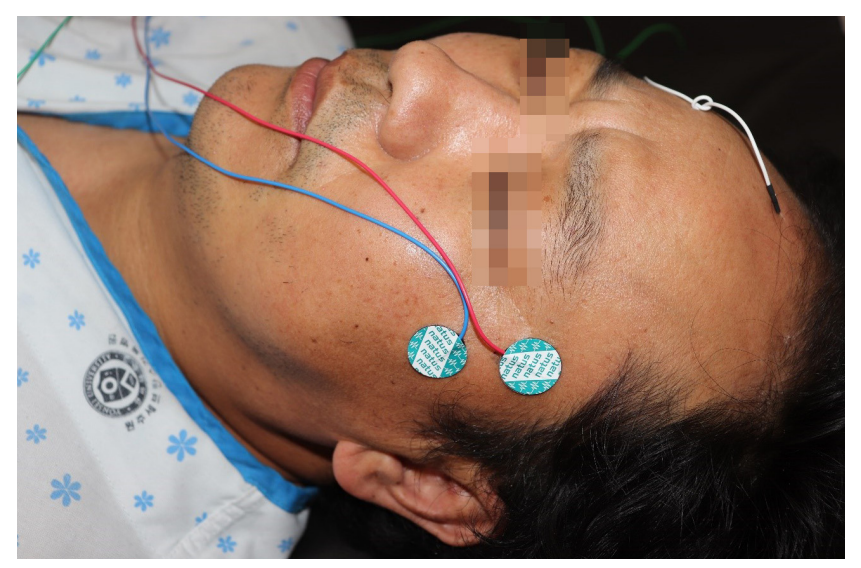

Fig. 3. Patient under trigeminal somatosensory evoked potential test. Electrodes connected to red and blue wires were surface nodes for stimulation. A needle electrode $12 \mathrm{~mm}$ in length was positioned on the forehead and used for recording. 
Table 1. Results of trigeminal somatosensory evoked potential and recovery time of each patients

\begin{tabular}{|c|c|c|c|c|c|}
\hline \multirow{2}{*}{ Patient no. } & \multirow{2}{*}{ Age (yr) } & \multicolumn{2}{|c|}{ Latency (ms) } & \multirow{2}{*}{$\begin{array}{l}\text { Differnce } \\
\text { value }\end{array}$} & \multirow{2}{*}{$\begin{array}{l}\text { Recovery } \\
\text { time (mo) }\end{array}$} \\
\hline & & Normal side & Affected side & & \\
\hline 1 & 51 & 15.6 & 15.9 & 0.3 & 1 \\
\hline 2 & 18 & 22.3 & 21.5 & 0.8 & 1 \\
\hline 3 & 77 & 17.0 & 15.8 & 1.2 & 3 \\
\hline 4 & 22 & 15.5 & 17.3 & 1.8 & 3 \\
\hline 5 & 46 & 21.2 & 19.3 & 1.9 & 1 \\
\hline 6 & 20 & 17.9 & 20.1 & 2.2 & 1 \\
\hline 7 & 17 & 16.6 & 17.4 & 0.8 & 2 \\
\hline 8 & 22 & 16.5 & 17.5 & 1.0 & 2 \\
\hline 9 & 39 & 19.7 & 21.6 & 1.9 & 2 \\
\hline 10 & 15 & 17.9 & 14.9 & 3.0 & 2 \\
\hline 11 & 18 & 21.1 & 29.9 & 8.8 & 2 \\
\hline 12 & 47 & 13.9 & 14.2 & 0.3 & 3 \\
\hline 13 & 18 & 17.2 & 18.2 & 1.0 & 3 \\
\hline 14 & 50 & 15.5 & 14.3 & 1.2 & 3 \\
\hline 15 & 36 & 20.0 & 17.8 & 2.2 & 3 \\
\hline 16 & 17 & 17.9 & 24.0 & 6.1 & 3 \\
\hline 17 & 24 & 18.6 & 25.7 & 7.1 & 4 \\
\hline 18 & 29 & 19.8 & 18.9 & 0.9 & 5 \\
\hline 19 & 51 & 16.8 & 22.6 & 5.8 & 12 \\
\hline 20 & 55 & 14.4 & 29.3 & 14.9 & 12 \\
\hline 21 & 29 & 12.7 & 18.1 & 5.4 & 6 \\
\hline 22 & 59 & 20.8 & 19.9 & 0.9 & $\mathrm{Nl}$ \\
\hline 23 & 76 & 18.5 & 19.9 & 1.4 & $\mathrm{Nl}$ \\
\hline 24 & 27 & 18.9 & 20.4 & 1.5 & $\mathrm{Nl}$ \\
\hline 25 & 27 & 12.3 & 11.1 & 1.2 & 1 \\
\hline 26 & 47 & 13.9 & 14.2 & 0.3 & 1 \\
\hline 27 & 47 & 13.9 & 10.2 & 3.7 & 5 \\
\hline 28 & 73 & 11.9 & 13.9 & 2.0 & 3 \\
\hline 29 & 17 & 14.7 & 23.0 & 8.3 & 12 \\
\hline 30 & 15 & 14.6 & 13.1 & 1.5 & 1 \\
\hline 31 & 15 & 11.1 & 12.5 & 1.4 & 1 \\
\hline 32 & 24 & 12.8 & 21.9 & 9.1 & 12 \\
\hline 33 & 50 & 12.8 & 13.7 & 0.9 & 1 \\
\hline 34 & 20 & 13.9 & 11.5 & 2.4 & 3 \\
\hline 35 & 20 & 13.9 & 14.1 & 0.2 & 1 \\
\hline 36 & 47 & 14.2 & 11.4 & 2.8 & 3 \\
\hline 37 & 39 & 13.4 & 12.7 & 0.7 & 1 \\
\hline 38 & 18 & 12.4 & 13.2 & 0.8 & 1 \\
\hline 39 & 17 & 13.8 & 18.9 & 5.1 & 6 \\
\hline 40 & 27 & 15.3 & 18.1 & 2.8 & 3 \\
\hline 41 & 68 & 15.9 & 16.4 & 0.5 & 1 \\
\hline 42 & 77 & 13.0 & 14.3 & 1.3 & 1 \\
\hline 43 & 60 & 13.8 & 14.5 & 0.7 & 1 \\
\hline 44 & 25 & 8.9 & 10.5 & 1.6 & 2 \\
\hline 45 & 68 & 12.9 & 13.0 & 0.1 & 2 \\
\hline 46 & 50 & 11.0 & 9.8 & 1.2 & 2 \\
\hline 47 & 59 & 14.7 & 12.9 & 1.8 & 1 \\
\hline 48 & 22 & 13.1 & 16.2 & 3.1 & 3 \\
\hline
\end{tabular}

$\mathrm{Nl}$, not identified.
Table 2. Difference value and recovery time of 2 groups divided by 3 months

\begin{tabular}{|c|c|c|c|c|c|}
\hline \multirow[b]{2}{*}{ Recovery time } & \multirow{2}{*}{$\begin{array}{l}\text { No. of } \\
\text { patients }\end{array}$} & \multicolumn{2}{|c|}{ Average latency (ms) } & \multirow{2}{*}{$\begin{array}{c}\text { Difference } \\
\text { value }^{\text {a) }}\end{array}$} & \multirow{2}{*}{$\begin{array}{l}\text { Average } \\
\text { recovery } \\
\text { time }(\mathrm{mo})^{\mathrm{al}}\end{array}$} \\
\hline & & $\begin{array}{l}\text { Normal } \\
\text { side }\end{array}$ & $\begin{array}{l}\text { Affected } \\
\text { side }\end{array}$ & & \\
\hline Recovery time $<3$ mo & 24 & 14.2 & 15.6 & 1.4 & 1.3 \\
\hline Recovery time $>3 \mathrm{mo}$ & 21 & 14.1 & 18.2 & 4.1 & 5.2 \\
\hline Not identified & 3 & 18.8 & 20.0 & 1.2 & - \\
\hline Total & 48 & 14.9 & 17.1 & 2.2 & 3.2 \\
\hline
\end{tabular}

Latency of first positive deflexion, difference value and recovery time indicate mean value of each group of patients. The average difference between latencies was 1.4 in the group that recovered within 3 months, and 4.1 in the group that recovered after 3 months. Difference value and recovery time were statistically relative on multivariate logistic regression model $(p<0.05)$.

${ }^{a}$ Mann-Whitney test.

cating the point of amplitude at post central gyrus of parietal lobe. Finally, the relationship between the latency difference and recovery time was tested using the Mann-Whitney test.

\section{RESULTS}

The average latency of the affected side and the unaffected side was $17.1 \mathrm{~ms}$ (range, 10.2-29.0 ms) and $14.9 \mathrm{~ms}$ (range, 11.6$27.6 \mathrm{~ms}$ ), respectively (Table 1). The average difference between the latencies was $2.42 \mathrm{~ms}$ (range, $0-7.8 \mathrm{~ms}$ ). The average recovery time was 3.2 months. Twenty-four patients recovered from ION damages within 3 months and 21 cases took longer to recover. The average difference between latencies was 1.4 in the group that recovered within 3 months, and 4.1 in the group that took longer than 3 months to recover (Table 2). The difference in latencies between the two groups was statistically significant using the multivariate logistic regression model $(p<0.05)$. All patients with abnormal TSEP testing result exhibited symptoms of hypoesthesia.

\section{DISCUSSION}

Peripheral nerves supply information on the surrounding environment and physiological conditions of the body to the central nervous system. Factors such as viral infection, systemic immune disease, nutritional deficiency, medication, radiation therapy and traumatic injury are well known causes of neurosensory change. In this study, we focused on neurosensory changes that originated from the mid-face fracture, which could cause ION damages.

Mid-face fracture, such as blow out fracture or zygomaticomaxillary fracture, frequently involve the infraorbital fissure, canal, or foramen. ION which stem from the trigeminal nerve $(\mathrm{CN} \mathrm{V})$ and maxillary nerve (CN V2) run through these ana- 
tomical locations and it is very common for patients who have mid-face fractures to present symptoms associated with sensory alterations of ION. It was reported that $24 \%$ to $94 \%$ of orbitozygomatic complex fracture cases are associated with ION damage [9-11]. ION span over a large area that covers the lower eyelids, cheeks, lateral sides of the nose, upper lip and nearby mucosa, gingiva and the teeth. Therefore, traumatic paresthesia over these areas has been considered indicative of mid-face fracture. Despite the relatively high incidence of ION damage following mid-face fracture, there are no standardized and objective methods to evaluate such damage [12].

Pin prick test or 2-point discrimination test are the current measurements. However, these tests are subjective tests and the outcomes depend on the cooperation of the patient and the examiner's interpretation. Moreover, measuring the severity of a nerve injury and predicting its progression are almost impossible using these tests. Therefore, many surgeons felt the necessity for a more effective diagnostic method that could be used for the diagnosis of ION damage, assessment of its progression and prediction of recovery $[9,13]$. In this study, we used the TSEP test to evaluate patients with mid-face fractures.

TSEP test is a type of nerve conduction study which can be used for lesions of the trigeminal nerve. When peripheral nerve is stimulated, the evoked potential is delivered to the trigeminal nuclei in the brain stem through the trigeminal ganglion. After that, the information is sent to ventral posteromedial thalamic nucleus to stimulate the post central gyrus of parietal lobe [5]. In our results, the first negative peak (N1) is inconsistent, potentially due to its relatively small amplitude. The first positive peak (P1) is more distinct and reliable. Therefore, P1 would appear to be the most appropriate latency check point [14]. Immediately after injury, axonal loss could show no latency shifts as the remaining axons conduct signal at the normal velocities [15]. It has been observed in other peripheral nerves that when there is damage, the impulses are amplified by the brain so that the final trace mimics to normal [16]. As described above, we compared the difference of the latency of evoked potential between the affected and unaffected side. As the difference gap becomes larger, the recovery time for ION damage also becomes longer.

In conclusion, after mid-face fracture, patients with ION damage showed prolonged latency when examined using the TSEP test. We provide evidence to show that the greater the latency, the slower the recovery. The TSEP test is an objective method to evaluate nerve injury and could be used to predict recovery rate of patients with ION damage. This test could be helpful for the explanation of a variety of clinical symptoms associated with infraorbital nerve damage.

\section{NOTES}

\section{Conflict of interest}

No potential conflict of interest relevant to this article was reported.

\section{Ethical approval}

The study was performed in accordance with the principles of the Declaration of Helsinki. Written informed consents were obtained.

\section{Patient consent}

The patients provided written informed consent for the publication and the use of their images.

\section{ORCID}

$\begin{array}{ll}\text { Woo Taik Hong } & \text { https://orcid.org/0000-0002-6764-8755 } \\ \text { Jin-hee Choi } & \text { https://orcid.org/0000-0003-0414-0679 } \\ \text { Ji Hyun Kim } & \text { https://orcid.org/0000-0001-9061-3350 } \\ \text { Yong Hun Kim } & \text { https://orcid.org/0000-0002-6092-4374 } \\ \text { Chae-Eun Yang } & \text { https://orcid.org/0000-0001-8128-791X } \\ \text { Jiye Kim } & \text { https://orcid.org/0000-0002-1724-4250 } \\ \text { Sug Won Kim } & \text { https://orcid.org/0000-0002-2354-7100 }\end{array}$

\section{REFERENCES}

1. Boffano P, Roccia F, Gallesio C, Karagozoglu KH, Forouzanfar T. Infraorbital nerve posttraumatic deficit and displaced zygomatic fractures: a double-center study. J Craniofac Surg 2013; 24:2044-6.

2. Kumar P, Godhi S, Lall AB, Ram CS. Evaluation of neurosensory changes in the infraorbital nerve following zygomatic fractures. J Maxillofac Oral Surg 2012;11:394-9.

3. Sakavicius D, Juodzbalys G, Kubilius R, Sabalys GP. Investigation of infraorbital nerve injury following zygomaticomaxillary complex fractures. J Oral Rehabil 2008;35:903-16.

4. Henssen DJ, Kurt E, Kozicz T, van Dongen R, Bartels RH, van Cappellen van Walsum AM. New insights in trigeminal anatomy: a double orofacial tract for nociceptive input. Front Neuroanat 2016;10:53.

5. Bennett AJ, Wastell DG, Barker GR, Blackburn CW, Rood JP. Trigeminal somatosensory evoked potentials: a review of the literature as applicable to oral dysaesthesias. Int J Oral Maxillofac Surg 1987;16:408-15.

6. Thygesen TH, Baad-Hansen L, Svensson P. Sensory action potentials of the maxillary nerve: a methodologic study with clinical implications. J Oral Maxillofac Surg 2009;67:537-42.

7. Fagade OO, Wastell DG. Trigeminal somatosensory evoked 
potentials: technical parameters, reliability and potential in clinical dentistry. J Dent 1990;18:137-41.

8. Ueki K, Nakagawa K, Marukawa K, Shimada M, Yoshida K, Hashiba Y, et al. Evaluation of upper lip hypoesthesia with a trigeminal somatosensory-evoked potential following Le Fort I osteotomy in combination with mandibular osteotomy. Oral Surg Oral Med Oral Pathol Oral Radiol Endod 2007;103:16974.

9. Pedemonte C, Basili A. Predictive factors in infraorbital sensitivity disturbances following zygomaticomaxillary fractures. Int J Oral Maxillofac Surg 2005;34:503-6.

10. Schultze-Mosgau S, Erbe M, Rudolph D, Ott R, Neukam FW. Prospective study on post-traumatic and postoperative sensory disturbances of the inferior alveolar nerve and infraorbital nerve in mandibular and midfacial fractures. J Craniomaxillofac Surg 1999;27:86-93.

11. Vriens JP, Moos KF. Morbidity of the infraorbital nerve following orbitozygomatic complex fractures. J Craniomaxillofac Surg
1995;23:363-8.

12. Barker GR, Bennett AJ, Wastell DG. Applications of trigeminal somatosensory evoked potentials (TSEPs) in oral and maxillofacial surgery. Br J Oral Maxillofac Surg 1987;25:308-13.

13. Fogaca WC, Fereirra MC, Dellon AL. Infraorbital nerve injury associated with zygoma fractures: documentation with neurosensory testing. Plast Reconstr Surg 2004;113:834-8.

14. Stohr M, Petruch F. Somatosensory evoked potentials following stimulation of the trigeminal nerve in man. J Neurol 1979; 220:95-8

15. Vriens JP, Pasman JW. Assessment of trigeminal nerve function by means of short-latency somatosensory evoked potentials after microneurosurgical repair. J Craniomaxillofac Surg 1994;22:156-62.

16. Parry GJ, Aminoff MJ. Somatosensory evoked potentials in chronic acquired demyelinating peripheral neuropathy. Neurology 1987;37:313-6. 